\title{
Importance of Human Resources Training in an Information Age
}

\author{
Azize Serap Tunçer \\ Ahi Evran University, Kırşehir, Turkey \\ serap@serapfirat.com
}

\begin{abstract}
The aim of this study is to display conceptually the relationship and interaction between matter of human resources training and the information age. Fast development from industrial community to an information community has occurred and organizations have been seeking ways to overcome this change. Human resources policy and human capital with enhanced competence will have direct impact on work performance; therefore, this paper deals with the increased importance of human resource management due to the fact that it nurtures human capital. Researching and scanning are used as a method in this study. Both local and foreign literature and expert views are employed - as much as one could be- in the making of the theoretical framework of this study.
\end{abstract}

Keywords: Human Resources, Information Age, Education, Organization, Occupation

\section{Introduction}

From the time of first scientific studies carried out by organizations until today, the social-economic environment that organizations are in has proportionally changed, in the frame of this development, organization style changed from Classical to Neo-Classical and finally to Modern Organization. The rapid change in the concepts, values and understandings throughout the modern world have made the organizations to make policies and targets towards adaptation to these changes.

In today's circumstances, organizations are maturing and becoming more and more complex. Another factor which is increasing as well is the level of competition. In order to face the competition and to survive, organization must use its own sources efficiently and optimize its performance by increasing the harmony between its components. At this competition, physical assets of the enterprises have lost their importance; however, non-physical information based values and the management of production of information processes have become a matter of primary importance. It must be well noted that attempts to improve of harmony between the components do not ensure an increase on total organizational performance.

This study evaluates the significance of educational process in organisation, which provides the success and its sustainbility for the enterprises in global competition arena. At the same time this concepts create a innovative structure which isn't in a short period but in a gradual period, the accumulation and evolution of social, cultural and economic background; at firms are achieved through suitable management structure; and conscious and disciplined efforts of managers and employees.

\section{Importance of education}

Certainly, education is most important tools for mankind and there is nothing more important than education for him. Rousseau, uses the fictional story of Emile and his tutor to outline his ideas. He explains his opinions as such in there: "Plants are fashioned by cultivation, man by education... We are born weak, we need strength; helpless, we need aid; foolish, we need reason. All that we lack at birth, all that we need when we come to man's estate, is the gift of education. This education comes to us from nature, from men, or from things. The inner growth of our organs and faculties is the education of nature, the use we learn to make of this growth is the education of men, what we gain by our experience of our surroundings is the education of things." (Rousseau, 2009: 11) This book was banned and publicly burned on its publication, but became a European bestseller and provided a basis for new education systems. 
ISSN 2411-9563 (Print) ISSN 2312-8429 (Online)
European Journal of Social Sciences Education and Research
September-December 2014

Volume 1, Issue 2

At the same time, education is the most powerful link which turns mass people into nation. Education obtains this power from the culture that is the component, carrier and the protector of it.

But what is the real importance of education in a modern age? Today education gives us the keys to career success, sometimes being a leader is more possible with better education. But education is a highly complex concept. Billington warns us about the difference between "educere" and "educare" process. "We may offer both the word educare and the word educere/these words may look and sound alike, but there is between them a gulf of meaning so broad that it is difficult to imagine that they can both cohabit in the context of a school's...... ." (Billington, 1988: 279-291) Thereby the author stresses to important role of autonomy. In his opinion: "Autonomy in a word, with educere as the dominant idea in education, its overriding aim will be that of producing not specialists in particular fields, but personal autonomy." (Billington, 1988: 282)

Autonomy is an important job component for job satisfaction. Moreover it is a basic leadership ability. Poper while criticizing Plato's leaders education thought, evaluate the leader abilities from the perspective of autonomy and intellectual independence. "Why is it that Plato does not wish his leaders to have originality or initiative? The answer, I think, is clear. He hates change and doesn't want to see that re-adjustments may become necessary. But this explanation of Plato's attitude does not go deep enough. In fact, we are faced here with a fundamental difficulty of the leader principle. The very idea of selecting or educating future leaders is self-contradictory. You may solve the problem, perhaps, to some degree in the field of bodily excellence. Physical initiative and bodily courage are perhaps not so hard to ascertain. But the secret of intellectual excellence is the spirit of criticism; it is intellectual independence. And this leads to difficulties which must prove insurmountable for any kind of authoritarianism. The authoritarian will in general select those who obey, who believe, who respond to his influence. (Popper, 1971: 134)

In such a society that most of the people -including the rulers- are under the influence of patrimonial structure, this concept gain more importance. Based on this reality for example the educational materials are being tried to teach chronology and historical phenomena strictly, boring and inaccurate books, lessons which are expert/teacher-centered and based on expert/teacher's instruction, not leading to research and thinking, and a dominant understanding based on memorization.

Especially in our complex world, the ability of criticism is a very important talent. Adorno regards education (Bildung) as a persisting area of conflict between an individual's autonomy and their adaptation to the demands of society. Education therefore entails an ongoing dialectic process between individual emancipation and the demands for submission to culture and society. Adorno's concept of (full) education is clearly connected to the idea of Bildung is seen as necessary to gain full and free individuality. Here, education does not aim to reach "useful" purposes or material aims. Rather it is designated to the long term interest of the subject and its personal development. (Adorno, 1951)

Sagan agrees with this view; and he shares a proclamation's of The Government of China and Chinese Communist Party in 1994 that read in part: "Public education in science has been withering in recent years. At the same time, activities of superstition and ignorance have been growing, and antiscience and pseudoscience cases have became frequent. Therefore, effective measures must be applied as soon as possible to strengthen public education in science." (Sagan, 1996b)

\section{Human resources training}

Organizations, due to numerous tasks dealt within, can be considered as quite complicated constructs in many concerns. In our global world; we observe that new values are adopted and new establishments and administrative structures are formed on this basis. Depending on this basis; the current Public Administration needs to renew itself within this course. The presence of the administrative institutions which are closer to the people has a fundamental role for detecting the social needs easily and offering efficient service.

Companies' continuity and conservation of their activities depends on their faster and more learning than their rivals. Importance of intellectual capital is constantly increasing for businesses. In the age of information, it can be observed that intangible assets, which include intellectual capital of businesses, overhaul tangible assets. Organizational knowledge, which consists of organizational rules, roles, customs, strategies, structures, technologies, cultural practices, capabilities etc., is the most valuable asset of today's organisations. Forming a learning organization requires changes in a lot of fields. These are a strong leadership, vision, team based structure, staff empowerment, information technologies, a participating strategy and organization culture. 
ISSN 2411-9563 (Print) ISSN 2312-8429 (Online)
European Journal of Social Sciences Education and Research
September-December 2014

Volume 1, Issue 2

Every employee has to learn the culture which belongs to its organization in order to live an individual of the organization and gain the cultural identification which the culture resources to.

When looking at the relationship and interaction between the matter of motivation and the administrator, it is seen that there is strong relation between whether that organization is public or private. Especially public administrators do not sufficiently motivate their employees. Essentially, the public administrators have positive attitudes towards maintaining motivation in fact, but they do not turn these attitudes into behavior and therefore reflect those positive attitudes. The reason is the adoption mostly of the traditional leadership style by the administrators and their display of their behaviors in light of the leadership values that prevails in the local bureaucratic culture.

Importance of training is reveals much in this situation. All workers must learn basic goal and mission their company's ideal and priorities. Philip Kotler, who the Financial Times on November 18, 2005 surveyed 1,000 executives in 25 countries on the Most Influential Business Writers/Management Gurus and him ranked fourth after Peter Drucker, Bill Gates, and Jack Welch. Kotler describes strategic marketing as serving as motivating all persons for a goal. He explain this concepts in interviews to Drucker, like this: "Marketing in a non-profit organization becomes effective when the organization is very clear about what it wants to accomplish, has motivated everyone in the organization to agree to that goal and to see the worthwhileness of that goal, and when the organization has taken the steps to implement this vision in a way which is costeffective, in a way which brings about that result." (Drucker, 63)

This policy known as a transperancy. Adoption of transparency in all organisation level is a necessity for the achievement of both own employee and public confidence. Organisations could enhance their corporate transparency levels through following globally accepted principles and guidelines. As a result, the employment of the in-service programs through the usage of the transformational leadership style among the modern leadership styles is recommended for the maintenance of motivation in order to turn the said administrators' positive attitudes into behavior.

Additionally we live in an era when the humanitarian values and the understandings towards it increases in individual wealth and happiness gain importance. For this reason Dudley Hafner stresses this opinion: "The strategy is how we use our resources to get the attention of that individual to do what it is we hope he or she will do... It is always focused on an individual. (Drucker, 72)

The rise in individuality and the effort to align this with the values of the organization has caused the organizational workforce approaches to change and adapt. Castells, while affirming this analysis, touches on the importance of the fact that this change in approach has opened new avenues to social interaction. "Torn by the internationalization of finance and production, unable to adapt to the networking of firms and the individualization of work, and challenged by the degendering of employment, the labor movement is weakened as a major source of social cohesion and worker's representation. It doesn't disappear, but it becomes, primarily, a political agent integrated into the realm of public institutitons." (Castells, 2009: 419)

\section{Information age and its technologies}

Today, all over the world, information services are becoming a featured matter and is considered as one of the impulsive forces of economic and social development. Manuel Castells is a big name in information society thinking and writing about Finland's Information Society. "In 2000 the IMD ranked Finland as the third most competitive economy in the world -the World Economic Forum (WEF) ranked it the most competitive. But the most distinctive feature of Finland is its combination of an information society and the welfare state. The Finnish welfare state includes totally free, high-quality, public education from kindergarten to the university (with one of the highest combined educational enrolment rates in the world), universal public health coverage (granted as a right based on citizenship), and a generous social system with universal retirement and unemployment insurance, which has made Finland a country with one of the smallest number of poor in the world." (Castells and Himenen, 2002: 12)

Informational transformation is a cultural and social, as well as a technical change and therefore, it should not be studied inside engineering discipline. But it needs a scientific interest. For example Maalouf complains about our education systems: "I am conscious of belonging to a generation that is highly privileged compared to every previous one, if only by dint of advances in medicine and information technology. But I cannot calmly enjoy the benefits of modernity if I am uncertain that generation to come will be able to enjoy them just as much." (Maalouf, 2011: XXII)

Sagan thinks similarly in this topic too. He says: "If we can't think for ourselves, if we're unwilling to question authority, then we're just putty in the hands of those in power. But if the citizens are educated and form their own opinions, then those 
in power work for us. In every country, we should be teaching our children the scientific method and the reasons for a Bill of Rights. With it comes a certain decency, humility and community spirit." (Sagan, 1996a)

Organizations can be regarded as systems which transforms inputs onto outputs by their human resources, technology and know-how. Especially, for the factories of our country which reached a significant technological level, the importance of information technologies have not to be underestimated. Informational institution transformation should be regarded as a project process, updated by periodical evaluations, in which basic needs and demands of the users and the strategies and formation policies are determined.

For this reason, education to employees is a long term process. Billington thinks to "Whatever view be held on the structure of the educational system, the basic question remains as to whether there is ever a time when a person's education should be seemed to be at an end." (Billington, 1988: 291)

Sociologist Manuel Castells has noted, "The future informational society is characterized by an increasing polarization of occupational structure. In the case of the United States, the Bureau of Labor Statistics included in its projections an analysis of the educational level required fort he 30 occupations that were expected to decline fastest between 1990 and $2005 \ldots$ The conclusion of the authors of the study is that "in general, a majority of the (groving) occupations require education or training beyond high school. In fact more than 2 out of 3 of the 30 fastest growing occupations, and nearly half of the 30 with the largest number of jobs added had a majority of workers with education or training beyond high school in 1990." (Castells, 2007)

While questioning the educational needs, some basic demands of the users should be taken into consideration when transforming into an informational-institution, the employees should be regarded as a customer or even a partner of the organization; they must believe in the benefits of education programs; they should be informed about the services of the informational-institution and they should also have the necessary equipment and training on how to use these services; otherwise they will never be able to reach the targets set on science and technology policies no matter how well.

\section{Conclusion}

Today human capital, which is accepted as one element of intellectual capital, is seen as the most important of these intangible assets. It is not possible to explain economic wellbeing by physical capital itself. The necessary measures must be taken in order to develop not only physical capital but also human capital and use it efficiently. Human resource management of firms play an essential role in utilizing human capital effectively.

\section{References}

[1] Adorno, T. W. (1951). Minima moralia: reflections from damaged life. Trans. E. F. N. Jephcott. London: NLB

[2] Billington, R. (1988). Living philosophy: an introduction to moral thought. London: Routledge.

[3] Castells, M. (2007). The rise of the network society: the information age: economy, society and culture V.1., 2nd Edition, Oxford, UK: Wiley Blackwell.

[4] Castells, M. (2009). The rise of the network society: the information age: economy, society and culture V.2. 2nd Edition, Oxford, UK: Wiley Blackwell.

[5] Drucker, P. F. (2011). Managing the non-profit organization: practices and principles, NY: Routledge.

[6] Maalouf, A. (2011). Disordered world: setting a new course for the twenty-first century. Trans. George Miller, NY: Bloomsbury.

[7] Popper, K. R. (1971). The open society and its enemies (the spell of plato., NJ: Princeton University Press.

[8] Rousseau, J. J. (2009). Emile: or on education. Auckland, NZ: Floating Press.

[9] Sagan, C. (1996a). Demon-haunted world: science as a candle in the dark. NY: Ballantine Books.

[10] Sagan C. (1996b). Does truth matter? science, pseudoscience, and civilization. Sceptical Inquirer, Volume 20.2, March / April from http://www.csicop.org/si/show/does truth matter science pseudoscience and civilization. 